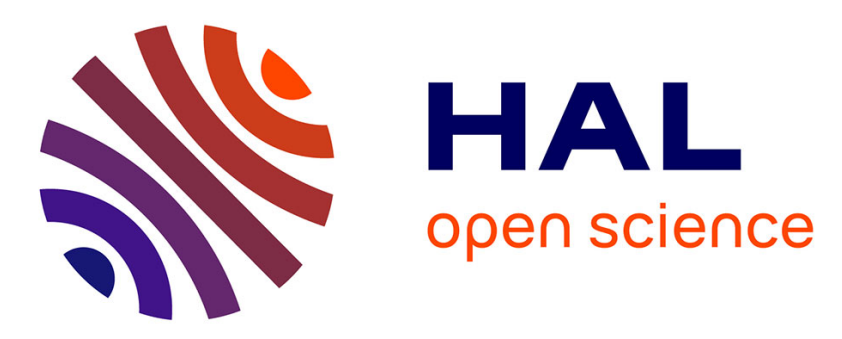

\title{
Local experimental investigations of the thermomechanical behavior of a coarse-grained aluminum multicrystal using combined DIC and IRT methods
}

Li Li, Jean-Michel Muracciole, Laurent Waltz, Laurent Sabatier, F Barou, Bertrand Wattrisse

\section{To cite this version:}

Li Li, Jean-Michel Muracciole, Laurent Waltz, Laurent Sabatier, F Barou, et al.. Local experimental investigations of the thermomechanical behavior of a coarse-grained aluminum multicrystal using combined DIC and IRT methods. Optics and Lasers in Engineering, 2016, 81, pp.1-10. 10.1016/j.optlaseng.2016.01.001 . hal-01287711

\section{HAL Id: hal-01287711 \\ https://hal.science/hal-01287711}

Submitted on 14 Mar 2016

HAL is a multi-disciplinary open access archive for the deposit and dissemination of scientific research documents, whether they are published or not. The documents may come from teaching and research institutions in France or abroad, or from public or private research centers.
L'archive ouverte pluridisciplinaire HAL, est destinée au dépôt et à la diffusion de documents scientifiques de niveau recherche, publiés ou non, émanant des établissements d'enseignement et de recherche français ou étrangers, des laboratoires publics ou privés. 


\title{
Local experimental investigations of the thermomechanical behavior of a coarse-grained aluminum multicrystal using combined DIC and IRT methods
}

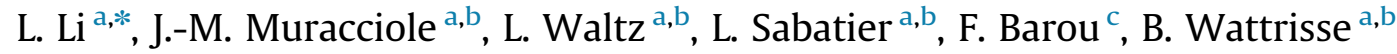 \\ ${ }^{a}$ Laboratoire de Mécanique et Génie Civil (LMGC), Montpellier 2 University, CNRS, France \\ ${ }^{\mathrm{b}}$ Laboratoire de Micromécanique et d'Intégrité des Structures (MIST), IRSN-CNRS-Montpellier 2 University, France \\ ${ }^{\mathrm{C}}$ Geosciences Montpellier, UMR 5243 CNRS-UMII CC 60, Place E. Bataillon, 34095 Montpellier Cedex 05, France \\ * Corresponding author. \\ E-mail address: li.li@umontpellier.fr (L. Li).
}

\begin{abstract}
A B S T R A C T
This paper presents Digital Image Correlation (DIC) and Infrared Thermography (IRT) methods to investigate the thermomechanical behavior of an aluminum at the microstructural scale. Electron BackScattered Diffraction (EBSD) is used to characterize the microstructure of a $3 \mathrm{~mm}$ thick specimen with centimetric grain size. This study combines the following imaging techniques: DIC to obtain displacement and strain fields during the test, and IRT to estimate temperature and heat source fields induced by the mechanical loading. Ultimately, the aim of this methodology is to provide energy balance during mechanical test at the scale of the microstructure, in order to propose thermomechanical constitutive modelling of crystalline plasticity.
\end{abstract}

Keywords:

Digital Image Correlation (DIC); Infrared Thermography (IRT); EBSD analysis; Crystal plasticity

\section{Introduction}

It is well known that even under a uniaxial tensile mechanical loading, heterogeneous spatial distributions of mechanical and thermal fields can be recorded due to anisotropic nature of the crystal slips $[1,2]$. Those heterogeneous phenomena have been widely studied using imaging techniques such as Infrared Thermography (IRT) and Digital Image Correlation (DIC) since the last two decades $[3,4]$. With the expanding application of infrared techniques and the progress achieved in the fields of optical techniques associated with quantitative image processing, the quality and precision of displacement and temperature full-field measurements have tremendously increased in the last decade $[5,6]$.

The microstructure of metals has also been widely investigated due to its relationship with the mechanical properties of materials. 
The development of automated Electron BackScattered Diffraction (EBSD) techniques [7] has contributed to better understanding of the microstructure evolution during plastic strain $[8,9]$.

Recently, samples containing only a small amount of grains in the micrometric range or in the millimetric range have been investigated to evaluate the deformation-induced plastic heterogeneities of polycrystals [10-14]. In this study, a face-to-face experimental setup was used to perform coupled full-field kinematic and thermal measurements on a coarse-grained aluminum polycrystal, in order to investigate the relationship between thermomechanical heterogeneities and material microstructure during mechanical loading using standard cameras. In that way, the relation between the microstructure evolution and the thermomechanical response of the materials during the mechanical test can be investigated.

The material and the sample preparation are firstly presented. Then, the EBSD microstructural analysis is given. The experimental setup performing full-field kinematic and thermal measurements will be briefly introduced. A spatial matching procedure to combine the data coming from the different acquisition systems is then presented. A specific methodology is proposed for the quantification of spatial matching uncertainty. Afterwards, experimental results associated with a tensile test are presented and discussed. Finally, the last section closes this paper with a short summary and conclusion.

\section{Experimental procedure}

\subsection{Sample preparation}

The as-received material used in this study consists in a $3 \mathrm{~mm}$ thick highly pure aluminum sheet (AA1050). The chemical composition of this material is reported in Table 1.

The first part of the sample preparation consists in a thermomechanical treatment which allows us to adjust the microstructure: grain size comprised between $100 \mu \mathrm{m}$ and $5 \mathrm{~mm}$ can be obtained [15].

The elaboration of Al specimen exhibiting "millimetric" grains requires the following three consecutive steps:

- Homogenization: Annealing at $560{ }^{\circ} \mathrm{C}$ during one hour in order to remove residual stress resulting from initial sheet forming operation.

- Critical hardening: Hardening of the sample up to around 1.8\% macroscopic strain, in order to store enough energy to achieve the dynamic recrystallization [15].

- Recrystallization and grain growth: Annealing at $620^{\circ} \mathrm{C}$ during one hour of the hardened sample to initiate dynamic recrystallization and grain growth up to the millimetric range.

The two main parameters for this thermomechanical treatment are the recrystallization temperature and the imposed strain. The plot in Fig. 1 represents the link between the imposed strain and the obtained grain size after annealing. It can be observed that, the strain level impacts directly the average grain size of the microstructure: an imposed strain well beyond the "critical strain" leads to a small grain size, whereas strains near the "critical strain" level generate a millimetric microstructure. However, a minimal strain

Table 1

Chemical composition of AA1050 aluminum [EN-AW 1050A] (Al, min wt \%: 99.5).

\begin{tabular}{lllllllll}
\hline Component & $\mathrm{Fe}$ & $\mathrm{Si}$ & $\mathrm{Mn}$ & $\mathrm{Ti}$ & $\mathrm{Cu}$ & $\mathrm{Mg}$ & $\mathrm{Zn}$ & Others \\
\hline Max (wt \%) & 0.4 & 0.25 & 0.05 & 0.05 & 0.05 & 0.05 & 0.07 & Each 0.03 \\
\hline
\end{tabular}

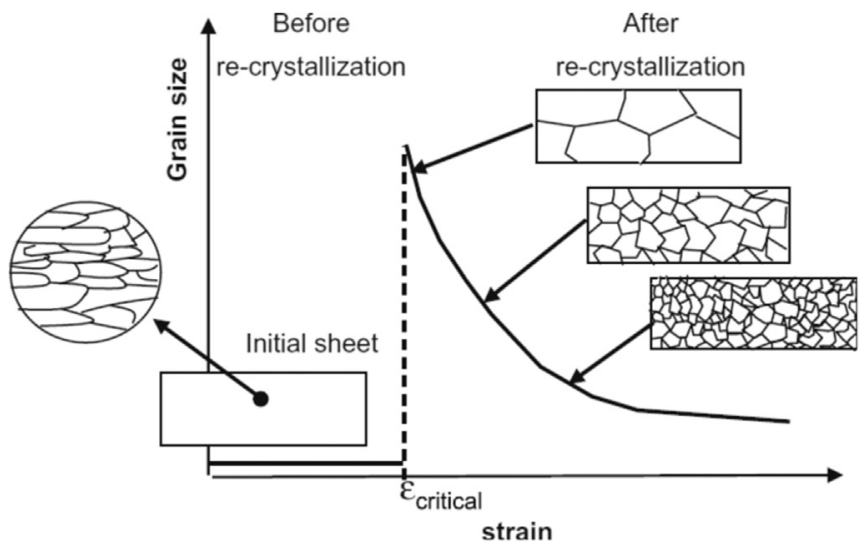

Fig. 1. Variation of grain size obtained after sample recrystallization as a function of applied tensile strain [16].

level is requested to activate dynamic recrystallization and grain growth.

After thermomechanical treatment, the sample must first be mechanically polished to remove residual surface deformations and scratches which could directly affect the quality of EBSD analysis. A mirror finish was assured by a mechanical polishing up to $1 \mu \mathrm{m}$ followed by an additional chemo-mechanical polish step using colloidal silica.

\subsection{EBSD analysis}

EBSD analysis is a powerful technique to provide informations about the microstructure, local grain orientation and texture measurements $[17,18]$. The analysis was performed on a JEOL JSM 5600 field emission gun SEM with a step of $100 \mu \mathrm{m}$, which provides sufficient spatial resolution to capture the fine description of the microstructure. The dimensions of the specimen were limited by the dimensions of the SEM chamber. According to these constraints, the sample dimensions have been fixed to $80 \times 20 \times 3 \mathrm{~mm}^{3}$.

After the thermomechanical treatment, Fig. 2 represents the initial grain orientation cartography of the specimen using for mechanical testing. Different grain orientations appear clearly in different colors, and the grain boundaries and the approximated average grain size can be provided directly from this map with the EBSD associated software (Oxford Instruments HKL CHANNEL 5). Before EBSD analysis, 3 carbon dots were deposited on the specimen surface in order to perform the spatial matching between EBSD and kinematic coordinate systems. You can notice that the specimen is clamped on its two ends, so that the left and right sides of the sample microstructure are not investigated in the following experimentation.

\subsection{Infrared Thermography and temperature field measurements}

Any specimen at a temperature greater than $0 \mathrm{~K}$ emits an infrared radiation, which can be related to its own temperature. In this work, the infrared camera Cedip Titanium with a focal plan array (FPA) of $512 \times 640 \mathrm{InSb}$ detectors is used. The physical size of pixel is $15 \mu \mathrm{m}$. By construction, this IR camera works in the spectral range from 3 to $5 \mu \mathrm{m}$. The IR images are recorded at a frequency of $20 \mathrm{~Hz}$ for this test. According to the manufacturer, the accuracy of the measured temperature is $20 \mathrm{mK}$ for an integration time of $1500 \mu \mathrm{s}$ and a working temperature of $25^{\circ} \mathrm{C}$. The spatial resolution is estimated at $92 \mu \mathrm{m}$ per pixel.

Concerning the calibration protocol, all infrared detectors are sensitive to the thermal radiations emitted by the observed body. When the target can be considered as a black-body, the energy of the thermal radiations can be directly related to the temperature 


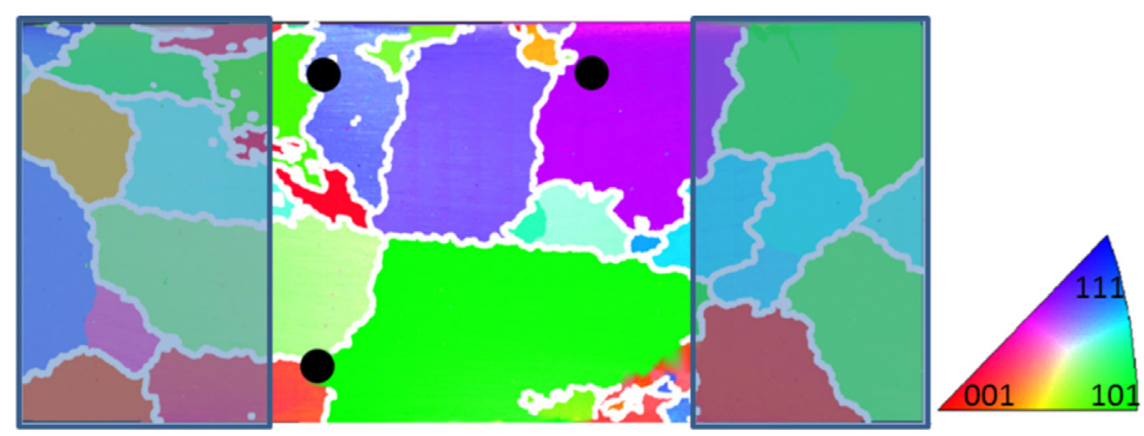

Fig. 2. Grain orientation map of the aluminum sample given by EBSD analysis before testing.

of the target's surface. The conversion from digital levels to temperatures consists in establishing the relationship between the digitized thermal emissions and the temperatures. The calibration law has been determined by exposing the detector array of the camera in front of a planar extended black-body, which is stable at different controlled temperatures and spatially uniform in term of temperature and emissivity. As we are to detect the local heterogeneities, the pixel calibration protocol $[19,20]$ is used to determine the individual calibration law of each pixel.

Moreover, it is well known that the calibration procedure and the experimental measurement are greatly influenced by many other parameters [21], i.e. working distance and temperature, as well as integration time. Therefore, a calibration is necessary for each test configuration. To avoid thermal drift and to obtain a better accuracy, the camera is switched on more than $4 \mathrm{~h}$ before beginning any measurement. The working area around the camera is protected from any reflection of the environment, and tests are performed with the light off.

Finally, in order to use IRT techniques, the surface emissivity of the sample placed in front of the IR camera is increased and homogenized using a mat black paint, in order to obtain an emissivity equal to the one of the black-body used for the calibration. Using this calibration protocol, the achieved accuracy on the thermal measurement is estimated to be $0.01 \mathrm{~K}$.

\subsection{Digital Image Correlation and displacement field measurements}

During the test, the visible images are recorded at a frequency of $40 \mathrm{~Hz}$ with a visible charge-coupled device (CCD) camera Phantom V12. This camera is composed of a $1280 \times 800$ matrix of detectors, whose physical size is $20 \mu \mathrm{m}$ for each detector. The observed surface of the sample, which is placed in front of the CCD camera, was speckled with black-white painting in order to obtain a random pattern. This pattern defines the local optical signature of each material surface element. Displacement fields of the sample during the mechanical testing are obtained through a classical local DIC algorithm (KelKins) performed on the captured visible images [22,23].

A rectangular Zone Of Interest (ZOI) defined in the reference (unstretched) image. The dimension of the ZOI is here $18 \times 20 \mathrm{~mm}^{2}$. It is divided into a regular rectangular grid of correlation patterns, hereafter called Correlation Zone (CZ). The size of the correlation patterns was fixed to $30 \times 30$ pixel, and the separation distance is 1 pixel, which allows the overlapping of adjacent correlation patterns. These two parameters define a mesh formed by the centers of each $\mathrm{CZ}$. The translational displacement field is obtained on the ZOI by matching the deformed image recorded at a time $t_{i}$ and the reference image recorded at the initial time $t_{0}$. Based on a pattern recognition [22], a normalized intercorrelation function is used to perform a direct correlation computation giving the two-dimensional displacement field maps for each time $t_{i}$. In this study, three seconds are necessary to compute each displacement field on a standard PC (HP Z400 Workstation).

The in-plane strain and strain-rate tensors are then derived by a numerical differentiation method based on a local least square approximation of the displacement fields. Here, for the strain field estimation, the displacement fields are approximated with a linear Approximation Function (AF) on time (using a $1.5 \mathrm{~s}$ time smoothing "window"), then a bilinear Approximation Function (AF) on space was used on a centered Approximation Zone (AZ) containing $41 \times 41$ measurements points (corresponding to a space smoothing "window" $\approx 1.7 \times 1.7 \mathrm{~mm}^{2}$ ). Indeed, the choice of the AF and AZ is important for this differentiation process, and the optimized choice depends on the signal-to-noise ratio, the regularity and the amplitude of the sought derivatives [24]. Obviously, these choices also influence the computational time, for instance, $18 \mathrm{~s}$ are required for each strain field computation. The accuracy of the procedure employed for displacement and strain calculation is discussed in detail in [22].

\subsection{Coupling EBSD, DIC and IRT data}

As mentioned previously, the sample is observed on one side with a CCD camera to perform DIC for the displacement field measurements, and the opposite side is recorded simultaneously by an IR camera in order to determine its surface temperature. As all data come from different acquisition systems, we have to perform their spatial and temporal matching to combine all experimental data. In the same manner, a spatial matching is also performed between the EBSD and the CCD data in order to get the microstructure of the material and to use it for the interpretation of kinematic and calorimetric measurements [25].

\subsubsection{Time correspondence}

Fig. 3 illustrates the experimental setup used in this study to perform fully coupled kinematic and thermal measurements. The main characteristics of the cameras are reported in Table 2. The two cameras used in this setup are materially synchronized in time using a specific home-made electronic device (SynchroCam) [6] allowing the simultaneous acquisition of images with temporal uncertainty lower than $100 \mu \mathrm{s}$. At the same time, this device allows us to digitize and record the analogical signals delivered by the sensors of the tensile machine (load, displacement).

\subsubsection{Spatial matching}

As we can notice in Fig. 3, the visible CCD camera is set perpendicularly to the sample on one side and the IR camera is placed on the opposite side. The optical axis of the two cameras were set perpendicularly to the frame of the testing machine, and therefore perpendicular to the sample surface. As previously mentioned, thin flat sample with "millimetric" grains are used in this investigation. The preliminary metallurgical etching on several specimens showed that the microstructure was very similar on both sides of the 


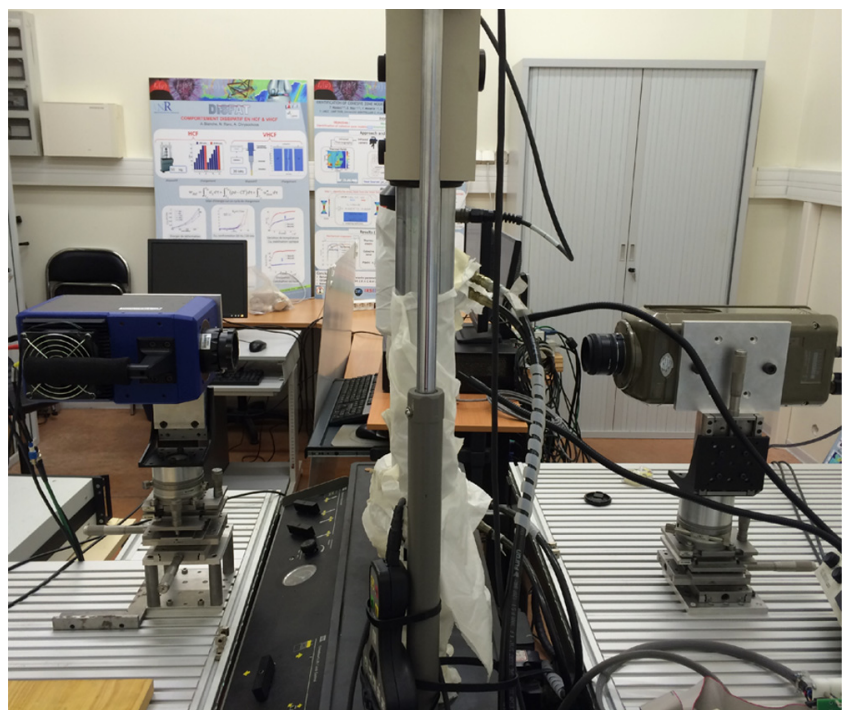

Fig. 3. Experimental setup.

Table 2

Main camera characteristics.

\begin{tabular}{llll}
\hline & Image size $($ pixel $)$ & Scale factor $(\mu \mathrm{m} /$ pixel $)$ & Frame rate $(\mathrm{Hz})$ \\
\hline IR & $512 \times 640$ & 92 & 20 \\
Visible & $1280 \times 800$ & 58 & 40 \\
EBSD & $1140 \times 505$ & 39 & - \\
\hline
\end{tabular}

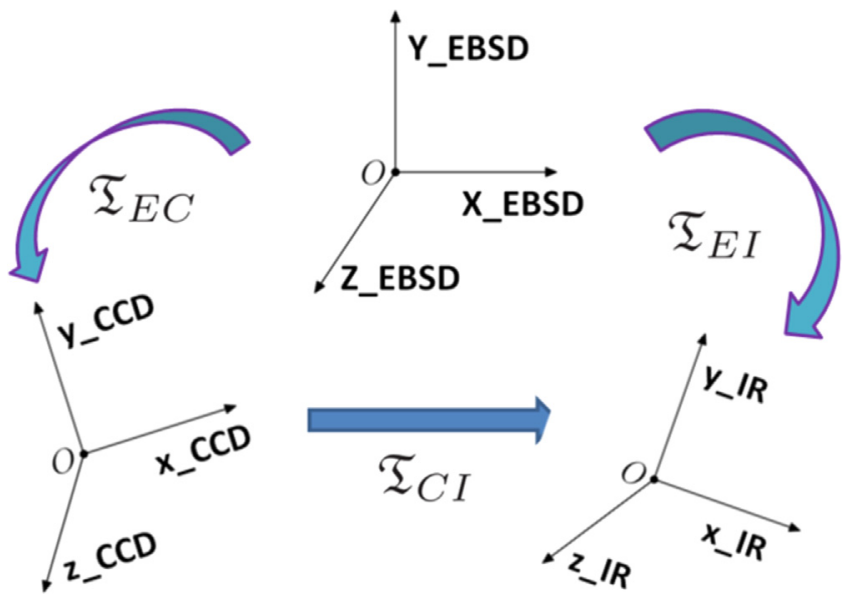

Fig. 4. Spatial transformation between different coordinate systems.

sample, which suggested that the sample had only one grain through the thickness. Finally, the EBSD observation is only performed on the sample surface located in front of the CCD camera. The grain boundaries are determined from the grain disorientation map given by the EBSD analysis, the grain contours are represented as white lines in Fig. 2. This "true" microstructure is manually simplified in order to obtain polygonal contours, shown as white solid lines in Fig. 5. It is important to note that the colors in this figure are not related to the grain orientation as represented in Fig. 2. In order to facilitate the subsequent meshing operation, the simplified microstructure keeps the large grains and regroups the smallest ones. Naturally, the level of "microstructural simplification" is chosen by the user and can be coarsened or refined at will.

This "simplified" microstructure is then projected on the CCD and IR images using the material transformation: $\mathfrak{I}_{E B S D \rightarrow C C D}$ and $\mathfrak{I}_{C C D \rightarrow I R}$ linking the coordinates in the EBSD, CCD and IR images in a

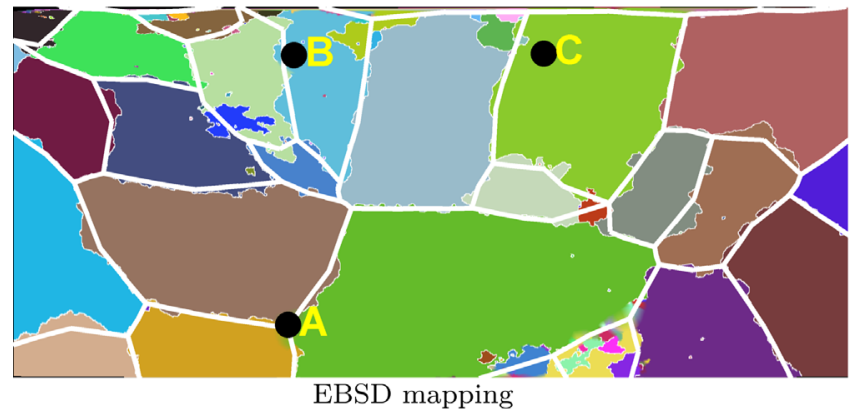

b

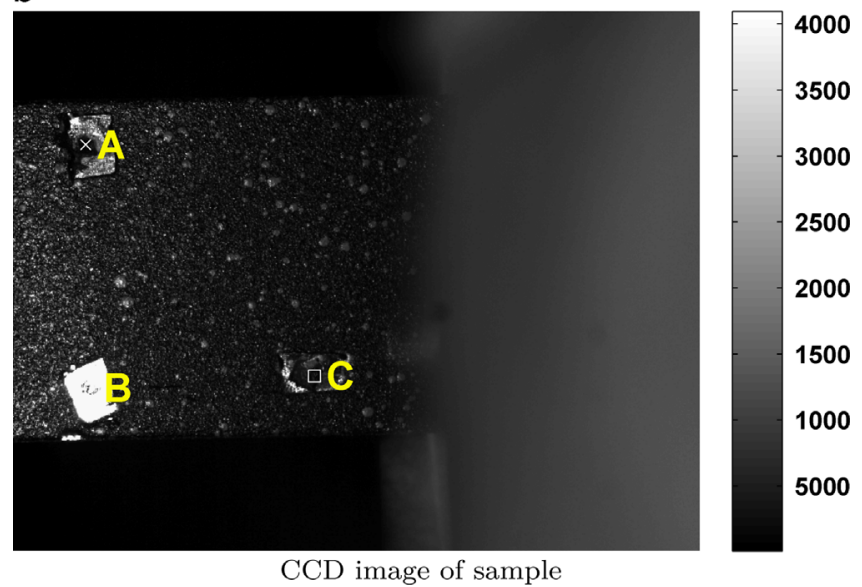

Fig. 5. Spatial matching between EBSD and CCD images: (a) EBSD mapping; (b) CCD image of sample.

the current configuration (see Fig. 4), denoted respectively $\left(x_{E B S D}\right.$, $\left.y_{E B S D}\right),\left(x_{C C D}, y_{C C D}\right)$ and $\left(x_{I R}, y_{I R}\right)$.

Supposing a perfect positioning of each acquisition device (CCD, IR, EBSD) perpendicular to the sample surface, the plane transformation from one coordinate system to another involves a translation, an expansion, a symmetry and a rotation. This transformation can be represented by the transformation matrix $\mathfrak{I}$ :

$$
\left(\begin{array}{c}
x_{\alpha} \\
y_{\alpha} \\
1
\end{array}\right)=? \overbrace{\left[\begin{array}{ccc}
a_{11}^{\alpha \beta} & a_{12}^{\alpha \beta} & a_{13}^{\alpha \beta} \\
a_{21}^{\alpha \beta} & a_{22}^{\alpha \beta} & a_{23}^{\alpha \beta} \\
0 & 0 & 1
\end{array}\right]}^{\mathfrak{I}} \times\left(\begin{array}{c}
x_{\beta} \\
y_{\beta} \\
1
\end{array}\right)
$$

In Eq. (1), $\left(x_{\alpha}, y_{\alpha}\right)$ and $\left(x_{\beta}, y_{\beta}\right)$ represent the coordinates in pixel of two coincident points in the coordinate systems of imaging devices $\alpha$ and $\beta, a_{i j}^{\alpha \beta}$ are the 6 coefficients of the transformation matrix to be identified between the two corresponding coordinate systems, with $(\alpha, \beta) \in[E B S D, C C D, I R]^{2}$.

Note that these transformations are purely geometric and that they link the coordinates of a given material point at a given time. In the following, $(X, Y)$ represents the coordinate in the Lagrangian configuration and $(x, y)$ depict the coordinates in the Eulerian one.

The microstructure is determined by EBSD before the test. It is thus known only in the reference configuration, $\left(X_{E B S D}, Y_{E B S D}\right)$. Consequently, the transformation $\mathfrak{I}_{E B S D \rightarrow C C D}$ must be determined in the reference configuration. The six parameters: $a_{i j}^{E B S D \rightarrow C C D}$ are determined by matching the coordinates of at least 3 corresponding points in the "reference" EBSD and CCD images. These 3 points (denoted A, B and C in Fig. 5) are materialized by the 3 carbon dots deposited on the sample surface before the EBSD acquisition (see Fig. 5). These dots were covered with small removable patches before painting the sample in order to get the speckle pattern necessary for the DIC computation. After painting, the patches 
were removed to let the dots appear in the CCD images (see Fig. 5b). After identification of the transformation matrix
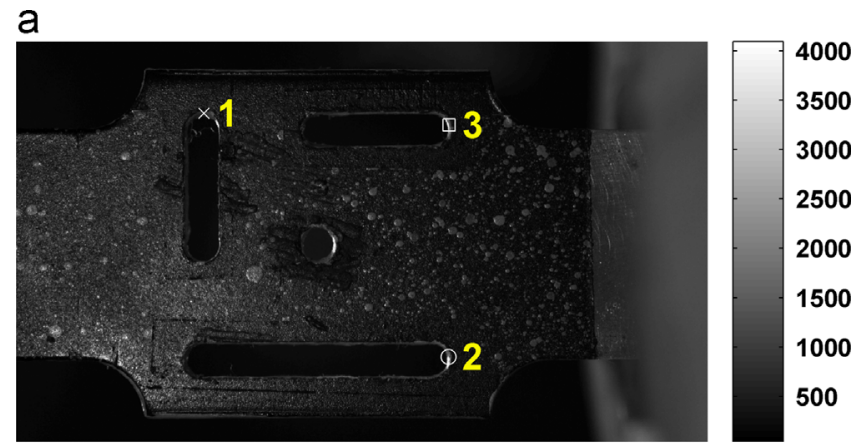

CCD image of specific calibrated target

\section{b}

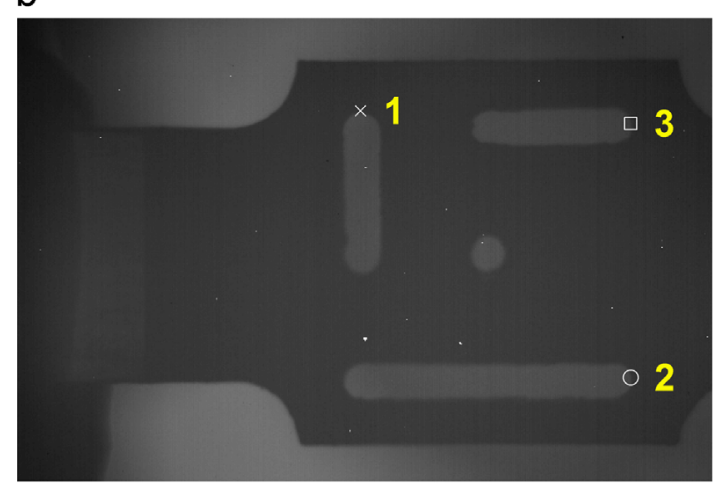

IR image of specific calibrated target

Fig. 6. Calibration target: (a) CCD and (b) IR image.
$\mathfrak{I}_{E B S D \rightarrow C C D}$, it is possible to transform each pixel of the EBSD map into the CCD coordinate system, and vice versa.

The geometric transformation $\mathfrak{I}_{C C D \rightarrow I R}$ is determined using IR and visible images of the same asymmetric calibration target represented in Fig. 6. The position of the 3 corresponding points (denoted 1,2 and 3 in Fig. 6) are used to determine the 6 coefficients $a_{i j}^{C C D \rightarrow I R}$. This calibration target is specifically designed to be simultaneously observed by the CCD and IR cameras. The spatial matching between the CCD and the IR cameras is performed by putting in correspondence a set of specific points that can be observed in both images. As mentioned previously, the corresponding transformation is purely geometric, so it remains constant throughout the test, as the cameras are not moved. For each pixel of the CCD/IR image, this transformation matrix $\left(\mathfrak{I}_{C C D \rightarrow I R}\right)$ ensures the passage between the two coordinate systems in the Lagrangian and Eulerian configurations.

These two transformations being linear, it is easy to "invert" them to get the inverse transformation $\mathfrak{I}_{I R \rightarrow C C D}$ or $\mathfrak{I}_{C C D \rightarrow E B S D}$, or to combine them to define, for example:

$\mathfrak{I}_{E B S D \rightarrow I R}=\mathfrak{I}_{C C D \rightarrow I R} \times \mathfrak{I}_{E B S D \rightarrow C C D}$

This approach ensures a geometrical spatial matching which allows us to track spatially (pixel by pixel) all material points in the three coordinate systems, and in both Lagrangian or Eulerian configuration.

With a Lagrangian viewpoint, the material microstructure given in the reference state by EBSD analysis can be physically tracked in the CCD coordinate system during the mechanical loading (see Fig. 7a and b), and this initial microstructure can also be clearly represented in the IR coordinate system (Fig. 7c).

The Eulerian configuration is determined using the kinematic measurements:

$x_{C C D}=X_{C C D}+u_{x}^{C C D}\left(X_{C C D}, Y_{C C D}\right)$

$y_{C C D}=Y_{C C D}+u_{y}^{C C D}\left(X_{C C D}, Y_{C C D}\right)$

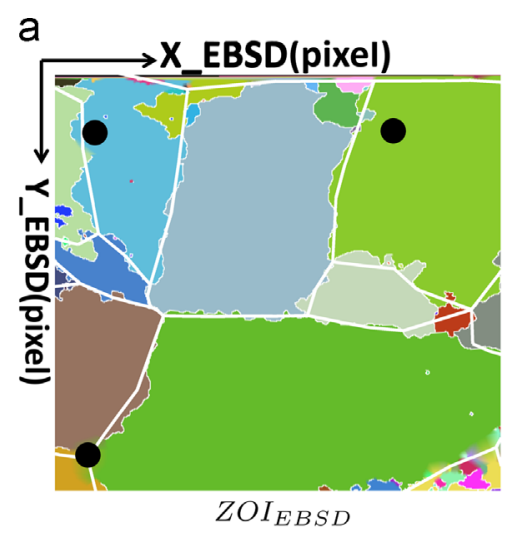

b

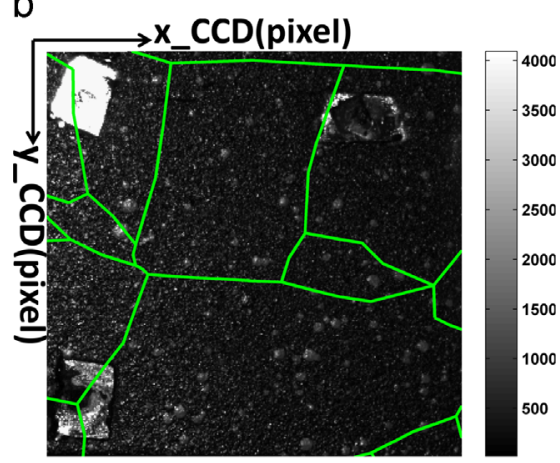

$Z O I_{C C D}$
C

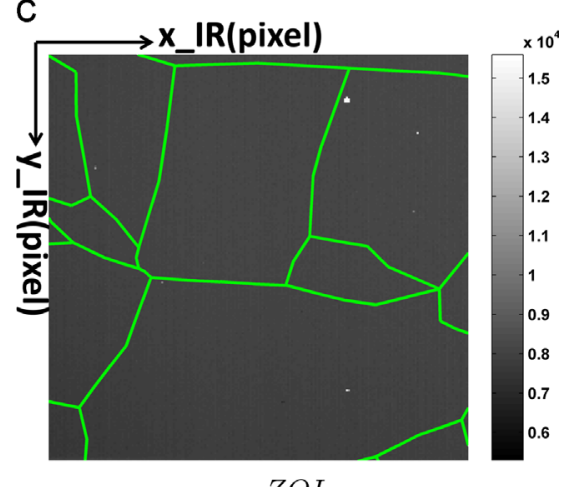

$Z O I_{I R}$

Fig. 7. Lagrangian representation of the microstructure in the different coordinate systems (CCD and IR images are given in Digital Level (DL)). 
and consequently the current microstructure in the IR image can be thus constituted as follow:

$$
\left(\begin{array}{c}
x_{I R} \\
y_{I R} \\
1
\end{array}\right)=? \overbrace{\left[\begin{array}{ccc}
a_{11}^{C C D \rightarrow I R} & a_{12}^{C C D \rightarrow I R} & a_{13}^{C C D \rightarrow I R} \\
a_{21}^{C C D \rightarrow I R} & a_{22}^{C C D \rightarrow I R} & a_{23}^{C C D \rightarrow I R} \\
0 & 0 & 1
\end{array}\right]}^{\mathfrak{I}_{C D \rightarrow I R}} \times\left(\begin{array}{c}
x_{C C D} \\
y_{C C D} \\
1
\end{array}\right)
$$

Naturally, it is important to quantify the incertitudes related to this quite long "measurement chain". The uncertainties associated with kinematic and thermal measurements are well described in $[26,27]$. We have thus focused our attention here on the spatial matching errors and their influence on the measurement.

We suppose that the chosen points for the determination of the three transformation matrices are exactly coincident, so that the three transformation matrices are strictly exact $\left(\mathfrak{I}_{E B S D \rightarrow I R}^{\text {exact }}\right.$, $\left.\mathfrak{I}_{C C D \rightarrow I R}^{\text {exact }}, \mathfrak{I}_{E B S D \rightarrow C C D}^{\text {exact }}\right)$.

We estimate the error in the location of the three matching points to be respectively 2.5 pixel, 2 pixel and 1.5 pixel for the EBSD, the CCD and the IR images. These values are defined as $10 \%$ of the dimension of the marks used in the identification of the three transformations. The actual positions of the three reference points in each image are then perturbed by random values (white, centered, Gaussian noise with a standard deviation equal to these "location errors") and the corresponding transformation parameters are determined using these "noisy coordinates". A set of 1000 random parameters were applied in order to estimate the three noisy transformation matrices $\left(\mathfrak{I}_{E B S D \rightarrow I R}^{\text {noisy }}, \mathfrak{I}_{C C D \rightarrow I R}^{\text {noisy }}, \mathfrak{I}_{E B S D \rightarrow C C D}^{\text {noisy }}\right)$.

The matching error is determined in the whole $Z O I_{E B S D}$. It is defined as the difference between the positions associated to the exact and noisy transformations. In practical terms, the location of each point in the $Z O I_{E B S D}$ is computed in the CCD and IR images using $\mathfrak{T}_{E B S D \rightarrow C C D}^{\text {exact }}$ and $\mathfrak{T}_{E B S D \rightarrow I R}^{\text {exact }}$ to get the actual positions of the $Z O I_{E B S D}$ points in the CCD and IR images. The same operation is performed using the $\mathfrak{I}_{E B S D \rightarrow C C D}^{\text {noisy }}$ and $\mathfrak{T}_{E B S D \rightarrow I R}^{\text {noisy }}$ transformation parameters. The error on the position due to the matching operations is defined as the difference between the actual and the noisy positions. Fig. 8 shows the histogram of spatial matching errors (between the $E B S D \rightarrow C C D$ and the $E B S D \rightarrow I R$ ) coordinate systems in $x$ and $y$ directions.

In Table 3, the Mean and the Standard Deviation (SD) errors are presented in pixel for the two spatial matchings. Additionally, these errors could be expressed in $\mu \mathrm{m}$ using the cameras' scale factors. For the $E B S D \rightarrow C C D$ correspondence, a mean SD of $3 \times$

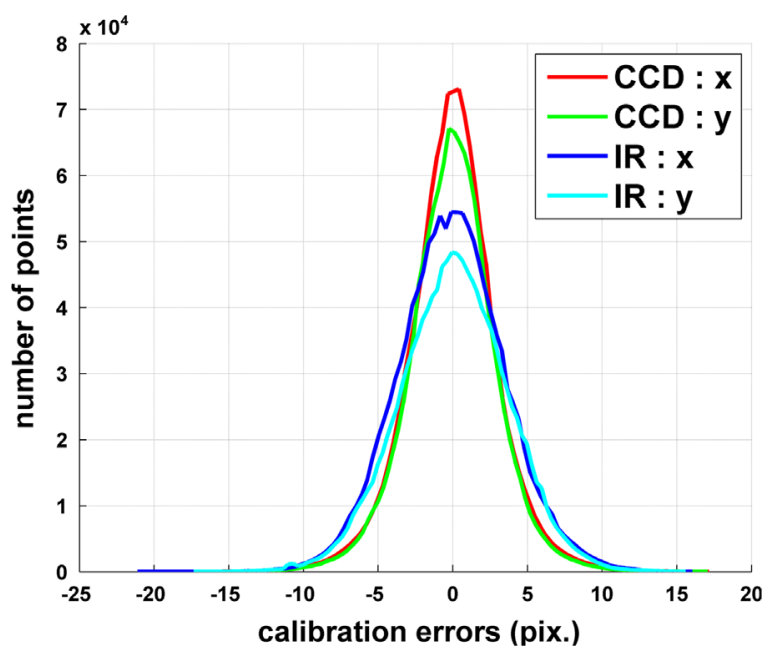

Fig. 8. Histogram of spatial matching errors from EBSD coordinate system to CCD and IR coordinate system.
Table 3

Spatial matching errors in pixel.

\begin{tabular}{llllll}
\hline \multirow{2}{*}{ Coordinate systems } & \multicolumn{2}{l}{ Mean error (pixel) } & & \multicolumn{2}{l}{ SD error (pixel) } \\
\cline { 2 - 3 } \cline { 5 - 6 } & $x$ & & & $x$ & $y$ \\
\hline$E B S D \rightarrow C C D$ & 0.01 & -0.06 & & 2.97 & 3.02 \\
$E B S D \rightarrow I R$ & 0.08 & -0.12 & & 3.69 & 3.66 \\
\hline
\end{tabular}

$58=174 \mu \mathrm{m}$ is obtained in the two directions, and a mean SD of $3.67 \times 92=337.6 \mu \mathrm{m}$ is obtained for $E B S D \rightarrow I R$ one. These errors are isotropic, and the $E B S D \rightarrow I R$ one is naturally far greater because of the low spatial resolution of IR camera, and the accumulation of errors between $E B S D \rightarrow C C D$ and $C C D \rightarrow I R$ matching.

\section{Experimental results and discussion}

We illustrate here the kind of results that can be obtained using the proposed methodology. The objective is not to fully characterize the thermo-mechanical behavior of the coarse-grained aluminum but to show the ability of the method to measure heterogeneous deformation and thermal fields.

In this study, mechanical tensile tests were performed at room temperature with a hydraulic testing machine: MTS-810 (frame: $100 \mathrm{kN}$, load cell: $25 \mathrm{kN}$ ), and the monitoring was done by controlling the displacement of the crosshead at a speed of $0.25 \mathrm{~mm} / \mathrm{s}$. The macroscopic mechanical responses (force-time and stressstrain) of the aluminum sample for a load-unload tensile test until failure are respectively represented in Fig. 9a and b. The 8 loadunload steps and the 1-s pause imposed between each loading/ unloading step are clearly visible on this curve.

The principles of the kinematic and thermal data processing are detailed in references $[22,24,28,29]$. The kinematic data processing provides the different components of the strain fields on the monitored surfaces for each recorded image. Using the infrared camera calibration protocol presented in [19], the maps of the temperature variation induced by the mechanical loading were deduced from the infrared images. DIC algorithms allow us to get the kinematic transformation between the current state and the reference configuration. It is thus possible to draw the kinematic results either in the reference or the deformed configuration (see Figs. 10a and 11a). Knowing the transformation $\mathfrak{I}_{C C D \rightarrow I R}$, it is also possible to construct the "Lagrangian" thermal field (see Fig. 10b) from the measured "Eulerian" thermal field (see Fig. 11b).

The equivalent Von Mises (VM) strain field and the temperature variation field at the loading step specified by the $A$ spot in Fig. 9 are respectively presented in Fig. 10a and b. For the same loading step, kinematic and thermal maps are presented in the Eulerian configuration in Fig. 11a and b.

On the strain maps (Figs. 10a and 11a), the area exhibiting a maximum value of strain can be localized. A local strain worth around $80 \%$ is recorded in the upper left corner of this map, with a global strain level reached about $14 \%$. This local strain value is consistent with the result reported in [11]. It is interesting to note that this area corresponds to an aggregate of small grains in the fracture zone. This can be seen in Fig. 12, where the last measured microstructure (before fracture) is superimposed to the picture of the fractured specimen. The dimension of this strain localization zone is in the same order of magnitude as the AZ (around $1.7 \times$ $1.7 \mathrm{~mm}^{2}$ here), suggesting that the actual strain level is probably higher. On the thermal maps, a strong heterogeneity can be observed in agreement with the microstructure (Figs. 10b and 11b). The sample temperature variation does not exceeded $1{ }^{\circ} \mathrm{C}$ 
a

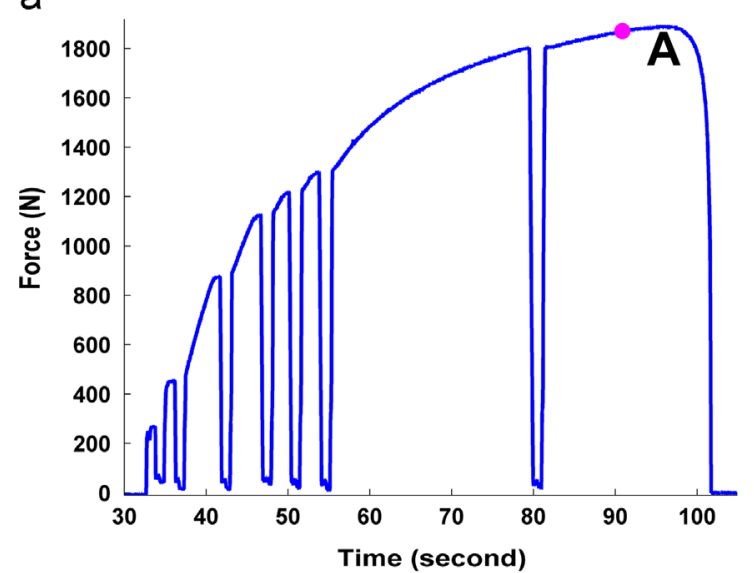

Imposed loading

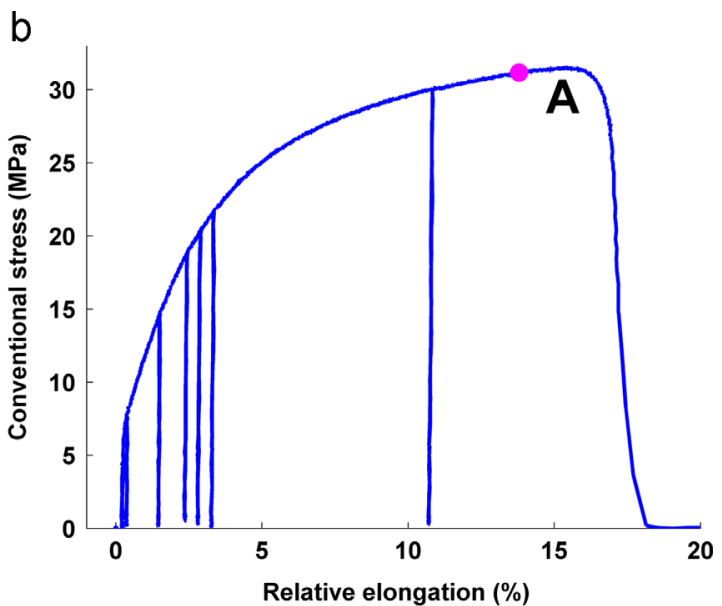

Conventional curve of tensile test

Fig. 9. Mechanical response of the sample: (a) imposed loading; (b) conventional curve of tensile test.

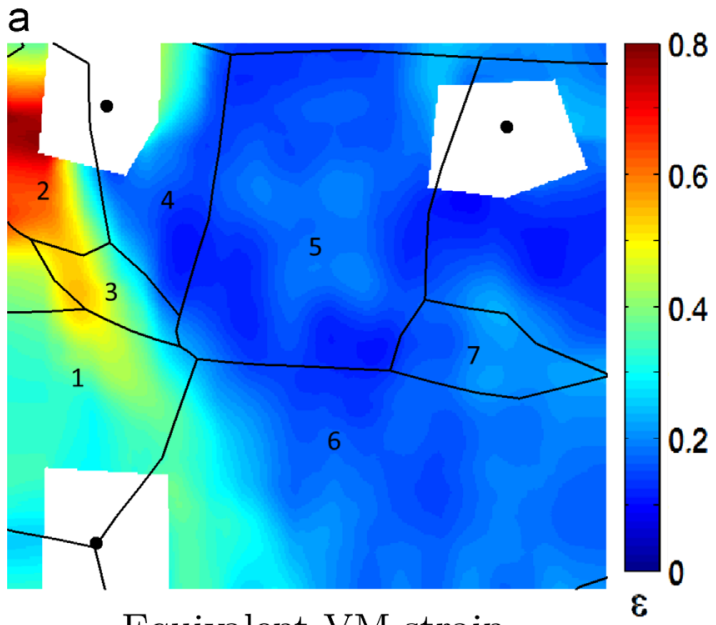

Equivalent VM strain b

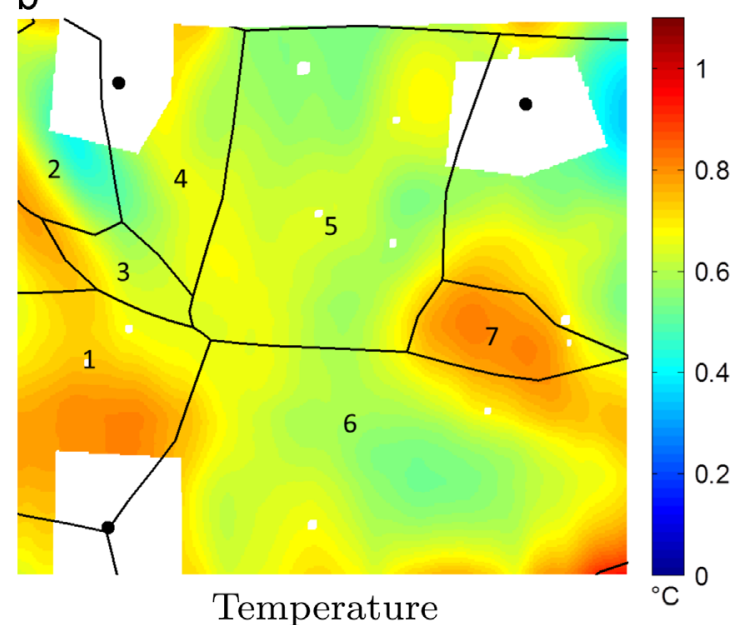

Fig. 10. Kinematic and thermal fields for loading step A in Lagrangian configuration $\left(\mathrm{ZOI}=18 \times 20 \mathrm{~mm}^{2}\right)$ : (a) equivalent VM strain; (b) temperature.

a

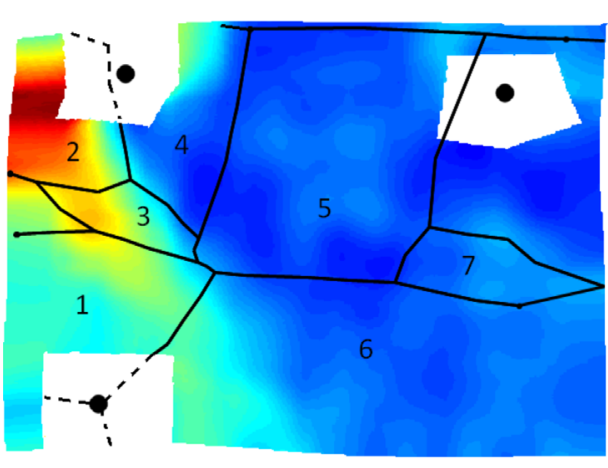

Equivalent VM strain

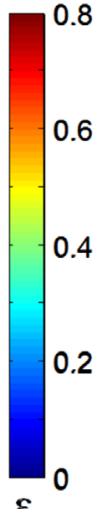

$\varepsilon$ b

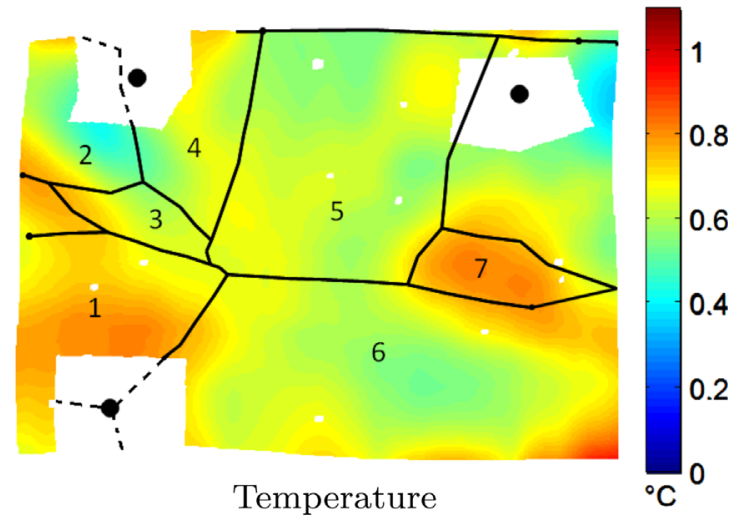

Fig. 11. Kinematic and thermal fields in Eulerian configuration for loading step A $\left(\mathrm{ZOI}=18 \times 20 \mathrm{~mm}^{2}\right)$ : (a) equivalent VM strain; (b) temperature.

because of the high thermal diffusivity of the material, which is also consistent with the result reported in the literature.

As it can be observed on Fig. 12, the important out-of-plane displacements are noticed for the sample in the final state. It was shown that, for the same experimental conditions, a $3 \mathrm{~mm}$ out-of- plane movement (equals to the sample thickness) generates $1 \%$ deformation which is much smaller than the deformation levels reached in the fracture zone. The main source of error in this zone is related to the coating degradation on the IRT or DIC faces, which has not been studied in detail in this work. 
Knowing the microstructure of the material in the CCD and IR frames, it is possible to determine the average evolution of strain and temperature per grain as a function of time. In our study, 7 "grains" can be monitored (see the numbering in the Figs. 10 and 11). Three grains have been selected to illustrate the temporal evolution of kinematic and thermal grain-averaged quantities: the most strained one (Grain 2), the hottest one (Grain 7), and one with small strain and temperature variations (Grain $\mathbf{5}$ ).

The average values per grain are computed by taking into account the spatial matching uncertainties in the CCD and the IR coordinate systems. As shown in Fig. 13, the physical grain boundaries given by EBSD analysis are plotted in black. According to Table 3 , in order to obtain reliable grain-averaged kinematic quantities, the real computational areas for each grain were contracted by 2 -times the SD error (2.97 pixel $\times 2=5.94$ pixel, representing $345 \mu \mathrm{m}$ ) towards the center of each grain, compared with the physical grain boundaries, as shown in Fig. 13. The same principle was applied for the thermal calculation with a 7.38 pixel (representing $679 \mu \mathrm{m}$ ) correction. These spatial matching corrections are not really negligible, especially for small grains. For example, Grain 3 is the smallest grain in this study with a surface of about $6.7 \mathrm{~mm}^{2}$. Taking into account the spatial matching uncertainties, we have respectively removed a half and two-thirds experimental data, for the kinematic and thermal calculation, to determine the average values for this grain. Indeed, introducing this spatial matching procedure allows us to provide a qualitative view of the grain-averaged information in the multicrystal, which is necessary to access the different thermomechanical variables at the microstructural scale.

After the computations of the local experimental data for each measurement step, their kinematic and thermal temporal

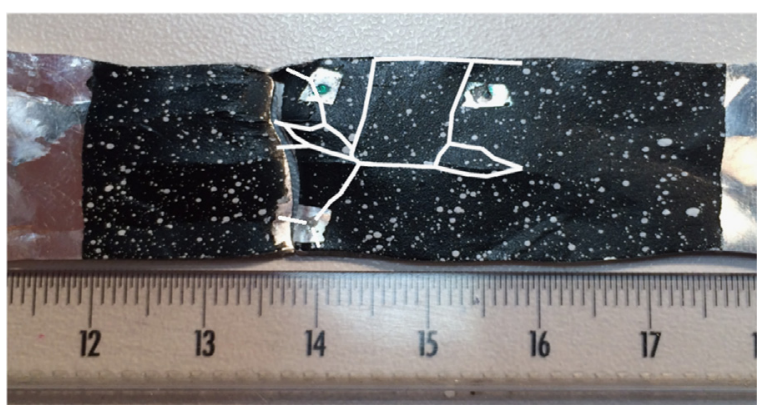

Fig. 12. Fractured experimental sample after the mechanical loading. evolutions are respectively drawn in Figs. 14 and 15. Various kinematic and thermal behaviors are clearly observed for these 3 grains.

As mentioned previously, the specimen was subjected to a load-unload tensile test until failure as shown in Fig. 9. These different load-unload steps can clearly be identified on both kinematic and thermal responses for each grain. In Fig. 14, we can notice the stationary plateaus of the grain-averaged equivalent strain for each unloading, including the $1 \mathrm{~s}$ pause. This plateau is particularly remarkable when the magnitude of the deformation is important, for example the 7th unloading occurs around $80 \mathrm{~s}$.

A localization of the equivalent strain is obviously observed in Fig. 14 for Grain 2 beyond the 6th loading step (55 s). This localization is much less evident for Grains $\mathbf{5}$ and 7. From a thermal point of view (Fig. 15), we can observe the thermo-elastic effects: temperature decrease during elastic-loading and temperature increase during elastic-unloading. During the plastic loading, the temperature rises regularly, as expected for a dissipative behavior Furthermore, a remarkable increase of temperature for these three grains is observed from $55 \mathrm{~s}$, the largest increase is particularly recorded for Grain 7.

Here, the Grain $\mathbf{2}$ which undergoes the largest equivalent strain is not the one that undergoes the highest temperature increase (Grain 7). In a thermomechanical point of view, it is possibly due to lower heat dissipation associated to higher energy storage for

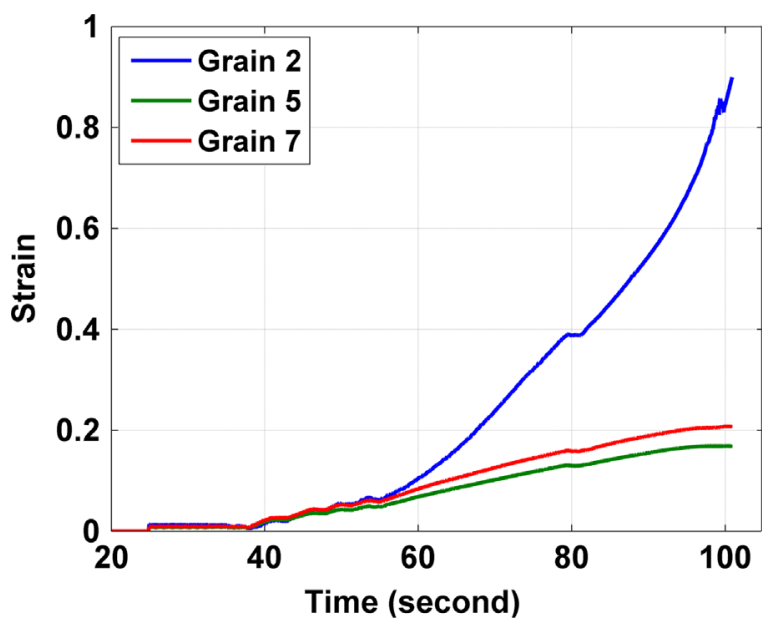

Fig. 14. Average equivalent strain per grain. a

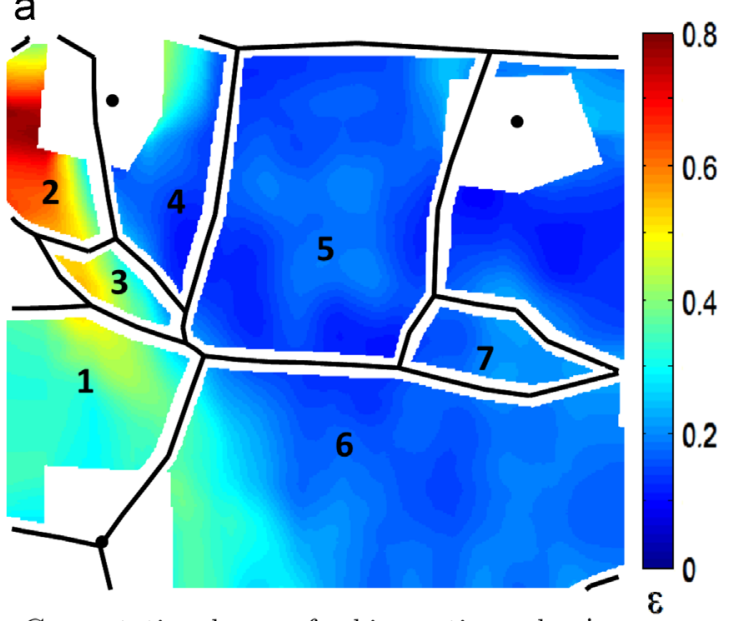

Computational areas for kinematic anal-ysis b

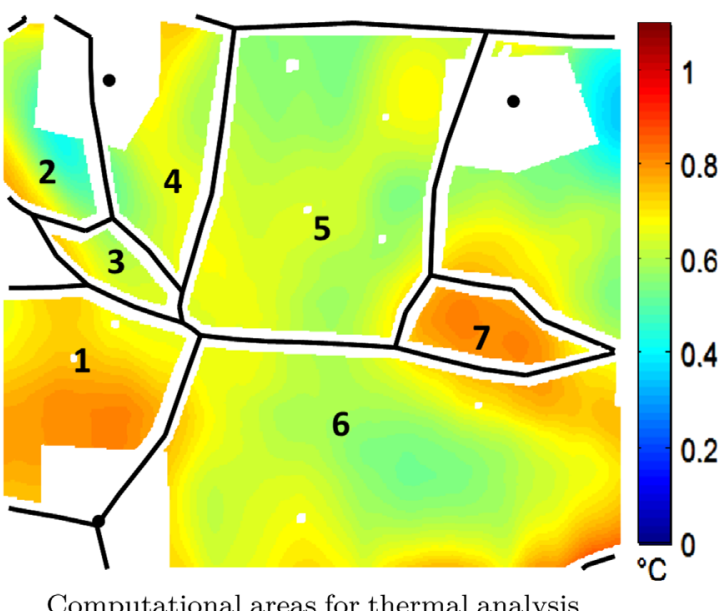

Computational areas for thermal analysis

Fig. 13. Computational areas for the grain-averaged quantity calculation: (a) computational areas for kinematic analysis; (b) computational areas for thermal analysis. 


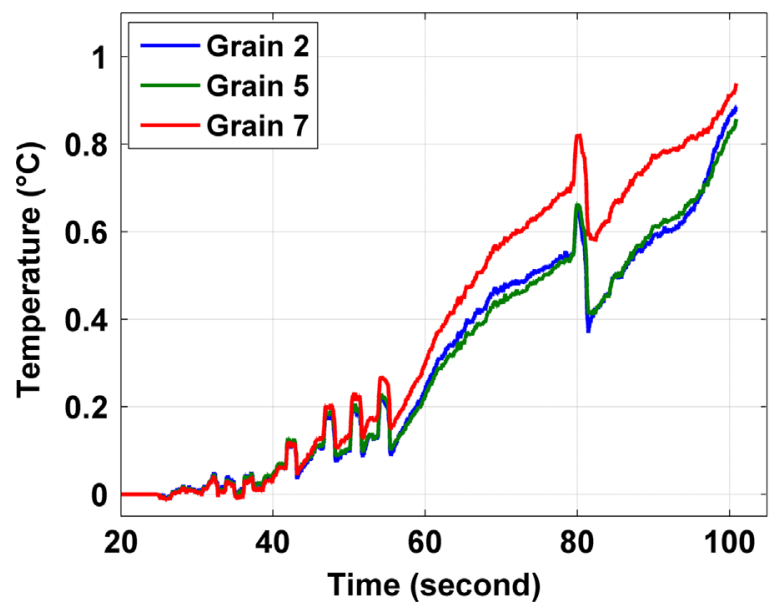

Fig. 15. Average temperature variation per grain.

the Grain 2, suggesting that from a qualitative point of view, the more the energy is stored, the more the microstructure is changed. A full calorimetric analysis would be required in order to validate such an hypothesis and to relate it to the "energy signature" of the plasticity mechanisms involved in the microstructure evolution. Naturally, during the strain plateaus between the loading and unloading, the thermal responses are not stationary due to heat losses by convection.

\section{Conclusion}

In this paper, a geometrical spatial matching procedure is presented that allows tracking spatially all the material points in three different imaging systems (EBSD, CCD, IR). Combining DIC and IRT methods, the experimental procedure described in this paper allows us to estimate the local distribution of strain and temperature fields in an aluminum polycrystal with centimetric grain size. This procedure reveals heterogeneities in the kinematic fields and in the thermal fields at the grain scale. Knowing the kinematic fields given by DIC analysis, and using the geometrical matching procedure, spatial heterogeneities were clearly observed in both the kinematic and the thermal fields in the Lagrangian and Eulerian configurations.

The proposed methodology allows quantifying strain and temperature localization. Here, the localization and subsequent fracture develops in a zone of the sample containing a large number of small grains. It is important to note that the scale of the material microstructure is similar to the one of the sample itself. Consequently, the results cannot be directly compared to classical microstructural effects, such as Hall-Petch effect [30,31] or nanocrystallization effect [32]. However, the results presented here can be explained by the following considerations:

- A single Hall-Petch relation may lose its validity for specimens with a thickness of about the crystallite size [33], especially if the number of grains across the thickness approaches unity [34].

- When a few grains are present across the width with grain size variation, the specimen deformation becomes anisotropic, and the response to the applied loading will depend on the free surface [35], on the number of grains involved and on the distribution of grain size and grain orientation $[11,12,36]$.

The matching procedure between the cameras is very important in this approach. It is performed here by matching the positions between coincident points in the different frames of reference associated to each type of image. A specific procedure is proposed to assess the reliability of this matching. The spatial matching accuracy can be easily improved by taking into account more markers and/or by reducing their dimensions. Another way of improving the matching procedure would be to introduce nonlinear terms in the transformation in order to account for possible distortions in the imaging devices. Moreover, in order to diminish the perturbation on the DIC measurement due to the markers, the carbon dots should be deposited on the edge of sample to preserve the observed surface.

A more complete calorimetric analysis should be performed in order to achieve a better understanding of the energy balance associated with the material transformation. This analysis would require the numerical processing of the heat equation described in references $[3,29,37,38]$. Such an analysis is currently being investigated.

Furthermore, a specific data processing method allowing thermal and displacement measurements while respecting the microstructure of the material (i.e. in each individual grain) is now being developed. This processing will allow obtaining local values of the different thermomechanical variables directly at the scale of the microstructure. This step is critical since it is necessary to obtain, in the long term, a local energy balance that can be used to characterize, at this scale, the thermomechanical consistency of classical polycrystal plasticity models.

\section{References}

[1] Jaoul B. Étude de la plasticité et application aux métaux. Dunod; 1965 URL 〈http://books.google.fr/books?id = EuLAygAACAAJ〉.

[2] Boas W, Hargreaves ME. On the inhomogeneity of plastic deformation in the crystals of an aggregate. Proc R Soc Lond Ser A: Math Phys Sci 1948;193 (1032):89-97. http://dx.doi.org/10.1098/rspa.1948.0035 arxiv.org/abs/http:// rspa.royalsocietypublishing.org/content/193/1032/89.full.pdf + html, URL 〈http://rspa.royalsocietypublishing.org/content/193/1032/89.abstract〉.

[3] Chrysochoos A, Maisonneuve O. Bilan énergétique en élastoplasticité grandes déformations, Comptes rendus de l'Académie des sciences. Série 2, Mécanique, Physique, Chimie, Sciences de l'univers, Sciences de la Terre 1985;300(20):98590 fre. URL 〈http://www.refdoc.fr/Detailnotice?idarticle $=12533990\rangle$.

[4] Sutton M, Wolters W, Peters W, Ranson W, McNeill S. Determination of displacements using an improved digital correlation method. Image Vis Comput 1983;1(3):133-9. http://dx.doi.org/10.1016/0262-8856(83)90064-1 URL 〈http://www.sciencedirect.com/science/article/pii/0262885683900641.

[5] Pan B, Qian K, Xie H, Asundi A. Two-dimensional digital image correlation for in-plane displacement and strain measurement: a review. Meas Sci Technol 2009;20(6):062001 URL 〈http://stacks.iop.org/0957-0233/20/i=6/a=062001〉.

[6] Chrysochoos A, Wattrisse B, Muracciole J-M, Kaim Y. Fields of stored energy associated with localiszed necking of steel. J Mech Mater Struct 4, 2009.

[7] Adams BL, Wright SI, Kunze K. Orientation imaging: the emergence of a new microscopy. Metall Trans A 1993;24:819-31. http://dx.doi.org/10.1007/ BF02656503 URL 〈http://dx.doi.org/10.1007/BF02656503〉.

[8] Delannay L, Mishin O, Jensen D, Houtte PV. Quantitative analysis of grain subdivision in cold rolled aluminium. Acta Mater 2001;49(13):2441-51. http: //dx.doi.org/10.1016/S1359-6454(01)00150-1 URL 〈http://www.sciencedirect. com/science/article/pii/S1359645401001501).

[9] Humphreys F. Review grain and subgrain characterisation by electron backscatter diffraction. J Mater Sci 2001;36:3833-54. http://dx.doi.org/10.1023/ A:1017973432592 URL 〈http://dx.doi.org/10.1023/A\%3A1017973432592〉.

[10] Zhao Z, Ramesh M, Raabe D, Cuitino A, Radovitzky R. Investigation of threedimensional aspects of grain-scale plastic surface deformation of an aluminum oligocrystal. Int J Plast 2008;24(12):2278-97. http://dx.doi.org/10.1016/j. ijplas.2008.01.002 URL 〈http://www.sciencedirect.com/science/article/pii/ S074964190800020X).

[11] Saai A, Louche H, Tabourot L, Chang H. Experimental and numerical study of the thermo-mechanical behavior of al bi-crystal in tension using full field measurements and micromechanical modeling. Mech Mater 2010;42(3):27592. http://dx.doi.org/10.1016/j.mechmat.2009.11.011 URL 〈http://www.science direct.com/science/article/pii/S0167663609001987).

[12] Badulescu C, Grédiac M, Haddadi H, Mathias J-D, Balandraud X, Tran H-S. Applying the grid method and infrared thermography to investigate plastic deformation in aluminium multicrystal. Mech Mater 2011;43(1):36-53. http: //dx.doi.org/10.1016/j.mechmat.2010.11.001 URL 〈http://www.sciencedirect. com/science/article/pii/S0167663610001535).

[13] Bodelot L, Charkaluk E, Sabatier L, Dufrénoy P. Experimental study of heterogeneities in strain and temperature fields at the microstructural level of polycrystalline metals through fully-coupled full-field measurements by 
digital image correlation and infrared thermography. Mech Mater 2011;43 (11):654-70. http://dx.doi.org/10.1016/j.mechmat.2011.08.006 URL 〈http:// www.sciencedirect.com/science/article/pii/S0167663611001554 $\rangle$.

[14] Li L, Muracciole J-M, Sabatier L, Waltz L, Wattrisse B. Analysis of the thermomechanical behavior of coarse-grained polycrystalline aluminum under tensile conditions. In: PhotoMechanics 2013, Montpellier, France; 2013. URL 〈http://hal.archives-ouvertes.fr/hal-00836313〉.

[15] Carpenter HCH, Elam CF. The production of single crystals of aluminium and their tensile properties. Proc R Soc Lond Ser A 1921;100(704):329-53. http: //dx.doi.org/10.1098/rspa.1921.0089 arXiv:http://rspa.royalsocietypublishing. org/content/100/704/329.full.pdf +html, URL 〈http://rspa.royalsocietypublish ing.org/content/100/704/329.short

[16] Philibert J, Vignes A, Brechet Y, Combrade P. Metallurgy: from mineral to material. Masson; 1998.

[17] Baudin T. L'analyse ebsd-principe et cartographies d'orientations, Techniques de l'ingénieur Essais métallographiques des métaux et alliages arXiv:base documentaire:TIB343DUO. URL 〈http://www.techniques-ingenieur.fr/basedocumentaire/materiaux-th11/essais-metallographiques-des-metaux-et-allia ges-42343210/analyse-ebsd-m4138>.

[18] Baudin T. L'analyse ebsd-application à l'etude de la deformation et de la recristallisation des matériaux métalliques, Techniques de l'ingénieur Essais métallographiques des métaux et alliages arXiv:basedocumentaire:TIB343 DUO, URL 〈http://www.techniques-ingenieur.fr/base-documentaire/materi aux-th11/essais-metallographiques-des-metaux-et-alliages-42343210/ana lyse-ebsd-m4138>.

[19] Honorat V, Moreau S, Muracciole J-M, Wattrisse B, Chrysochoos A. Calorimetric analysis of polymer behaviour using a pixel calibration of an IRFPA camera. Quant InfraRed Thermogr J 2005;2(2):153-71. http://dx.doi.org/10.3166/ qirt.2.153-171 arXiv:http://www.tandfonline.com/doi/pdf/10.3166/qirt.2.153171, URL 〈http://www.tandfonline.com/doi/abs/10.3166/qirt.2.153-171〉.

[20] Chrysochoos A. An overview of infrared analysis of thermomechanical behavior of materials. In: 11th international conference on QIRT; 2012.

[21] Pron H, Bissieux C. Focal plane array infrared cameras as research tools. Quant InfraRed Thermogr J 2004;1(2):229-40. http://dx.doi.org/10.3166/ qirt.1.229-240 arXiv:http://www.tandfonline.com/doi/pdf/10.3166/qirt.1.229240, URL/http://www.tandfonline.com/doi/abs/10.3166/qirt.1.229-240〉.

[22] Wattrisse B, Chrysochoos A, Muracciole J-M, Nemoz-Gaillard M. Analysis of strain localization during tensile tests by digital image correlation. Exp Mech 2001;41:29-39. http://dx.doi.org/10.1007/BF02323101 URL 〈http://dx.doi.org/ $10.1007 /$ BF02323101/.

[23] Wattrisse B, Chrysochoos A, Muracciole J-M, Nemoz-Gaillard M. Kinematic manifestations of localisation phenomena in steels by digital image correlation. Eur J Mech-A/Solids 2001;20(2):189-211. http://dx.doi.org/10.1016/ S0997-7538(00)01113-X URL 〈http://www.sciencedirect.com/science/article/ pii/S099775380001113X)

[24] Chrysochoos A, Huon V, Jourdan F, Muracciole J-M, Peyroux R, Wattrisse B. Use of full-field digital image correlation and infrared thermography measurements for the thermomechanical analysis of material behaviour. Strain
2010;46(1):117-30. http://dx.doi.org/10.1111/j.1475-1305.2009.00635.x URL $\langle$ http://dx.doi.org/10.1111/j.1475-1305.2009.00635.x〉.

[25] Chrysochoos A, Muracciole J-M, Wattrisse B. Experimental analysis of strain and damage localization. Elsevier; 2000. p. 41-51.

[26] Bornert M, Brémand F, Doumalin P, Dupré J-C, Fazzini M, Grédiac M, et al. Assessment of digital image correlation measurement errors: Methodology and results. Exp Mech 2009;49:353-70. http://dx.doi.org/10.1007/ s11340-008-9204-7 URL 〈http://dx.doi.org/10.1007/s11340-008-9204-7〉.

[27] Poncelet M, Witz J-F, Pron H, Wattrisse B. A study of IRFPA camera measurement errors: radiometric artefacts. Quant InfraRed Thermogr J 2011;8 (1):3-20. http://dx.doi.org/10.3166/qirt.8.3-20 arXiv:http://dx.doi.org/10. 3166/qirt.8.3-20, URL 〈http://dx.doi.org/10.3166/qirt.8.3-20〉.

[28] Wen S. Identification expérimentale de modèles de zones cohésives à partir de techniques d'imagerie thermomécanique [these], Université Montpellier IISciences et Techniques du Languedoc. URL 〈http://tel.archives-ouvertes.fr/tel00854103); December 2012.

[29] Blanche A. Effets dissipatifs en fatigue a grand et tres grand nombre de cycles [Ph.D. thesis], Universite Montpellier II; 2012.

[30] Hall EO. The deformation and ageing of mild steel: III discussion of results Proc Phys Soc: Sect B 1951;64(9):747 URL 〈http://stacks.iop.org/0370-1301/64/ $\mathrm{i}=9 / \mathrm{a}=303\rangle$.

[31] Petch NJ. The cleavage strength of polycrystals. J Iron Steel Inst 1953:25-30.

[32] Ke L, Jian L. Surface nanocrystallization (snc) of metallic materialspresentation of the concept behind a new approach. J Mater Sci Technol 1999; $15: 193-7$.

[33] Janssen P, de Keijser T, Geers M. An experimental assessment of grain size effects in the uniaxial straining of thin al sheet with a few grains across the thickness. Mater Sci Eng: A 2006;419:238-48. http://dx.doi.org/10.1016/j. msea.2005.12.029 URL 〈http://www.sciencedirect.com/science/article/pii

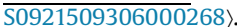

[34] Geers M, Brekelmans W, Janssen P. Size effects in miniaturized polycrystalline \{FCC samples: strengthening versus weakening. Int J Solids Struct 2006;43 (24):7304-21. http://dx.doi.org/10.1016/j.ijsolstr.2006.05.009 size-dependent Mechanics of Materials. URL 〈http://www.sciencedirect.com/science/article/ pii/S0020768306001673).

[35] Thompson AW. Polycrystal hardening, Work hardening in tension and fatigue 89126TMS-AISME; 1977.

[36] Baudoin P. Caractérisation et identification de propriétés de matériaux métalliques a gradients de microstructure [Ph.D. thesis], Universite Lille 1. URL 〈http://www.theses.fr/2015LIL10015〉; 2015.

[37] Chrysochoos A, Maisonneuve O, Martin G, Caumon H, Chezeaux J. Plastic and dissipated work and stored energy. Nucl Eng Des 1989;114:323-33.

[38] Chrysochoos A, Louche H. An infrared image processing to analyse the calorific effects accompanying strain localisation. Int J Eng Sci 2000;38(16):1759-88. http://dx.doi.org/10.1016/S0020-7225(00)00002-1 URL〈http://www.science direct.com/science/article/pii/S0020722500000021 $>$. 